n the dark story of Marc Hauser, the evolutionary psychologist who was last week revealed to have committed scientific misconduct, there is perhaps one bright light: the courage of the young researchers who alerted the university to their concerns over how the professor was interpreting his data.

Hauser is a star in his field and an intellectual celebrity. Members of his lab at Harvard University in Cambridge, Massachusetts, took a huge professional risk to raise complaints against such a formidable figure.

Graduate students and postdocs are often in the best position to witness misconduct. Unfortunately, their careers are also the most vulnerable to collateral damage from such transgressions, particularly when the accused is a mentor. A young scientist's reputation is tethered to the successes and failures of his or her adviser, and when that adviser is accused of misconduct, trainees can also be viewed with suspicion.

The dozens of graduates and postdocs who have passed through Hauser's hands now face an uncertain future. Some have had to switch labs. Others are ready to look for faculty positions, but don't know how to explain their status to hiring committees. Should they openly discuss Harvard's three-year investigation? Some are new faculty members anxiously applying for grants. How should they list their publications with Hauser? When will it be safe for them to submit papers co-authored with him? These are the dilemmas that play out behind the headlines in nearly every misconduct case.

In the days following the first reports of the Hauser investigation in mid-August, Harvard's refusal to release its findings only increased the pressure on these young scientists. The university offered no clues as to whether other researchers or publications would be implicated.

Fortunately, the silence did not last, and on Friday Harvard released a summary of the conclusions reached by its internal investigation. The report found problems with the way that Hauser, whose work connects the observed behaviour of non-human primates to the evolution of key human characteristics such as morality, handled data and reported results. The university's statement stressed that Hauser alone was responsible for the eight instances of misconduct uncovered, and listed only three papers tarnished by the discovery.

Harvard had been pummelled in the press for its reticence, but it is common and sometimes necessary for universities to sit on the results of internal misconduct investigations. This is particularly true when the case is complex - as they often are - and the findings subject to challenge, or when other researchers have been implicated. Indeed, the US Office of Research Integrity (ORI), which monitors investigations of researchers who are funded by the National Institutes of Health, asks institutions not to make their investigations public until the ORI has completed its own assessment. This can delay a verdict for weeks or even years after the university completes its own investigation.

There is a practical reason for this secrecy: if the ORI needs to convene a hearing, the office does not want potential witnesses to be tainted by exposure to prior conclusions.

In this case, following two weeks of pressure from scientists and the press, Harvard was right to release key details of its investigation ahead of schedule. The move does not entirely lift the burden on Hauser's young associates, but it can perhaps ease their load until a full account of his misconduct is brought to light.

Such relief is a welcome reward. At a laboratory where there are now question marks over both animal and human behaviour, the young researchers acted as true scientists should.

\section{Australia's mixed climate}

\section{A coalition government could be what the country needs to make headway on an emissions policy.}

$\Lambda$ t first glance, there are notable parallels between the outcomes of the Australian general election last weekend and the British election held in May. Both electorates rejected the incumbent party, but failed to endorse the main opposition in sufficient numbers to hand them a majority.

As Nature went to press, the power-broking in Australia was yet to resolve into a clear picture of the likely political landscape, although, as in Britain, the expected outcome is a coalition government.

Science barely featured in either election, but the issue of climate change lurked behind the scenes. Both elections returned historic representation from the Green party.

Australia's politicians have failed its people on climate change. Despite opinion polls that consistently indicated popular support for policies to tackle greenhouse-gas emissions, the country's two main parties have both weakened their stance on the issue of late.

The conservative Liberals ousted former leader Malcolm Turnbull last year over his support for a planned emissions-trading scheme, and replaced him with climate sceptic Tony Abbott. Soon after, the Labor party dumped the scheme altogether, followed by Prime Minister Kevin Rudd. The lukewarm approach to climate by his successor, Julia Gillard, seems to have contributed to the electoral success of the Australian Greens.

By contrast, Britain's three big parties raced to outdo each other on ambitious climate pledges in the lead-up to the election, a political arms race that leaves the resulting Conservative-Liberal union ahead of much of the public when it comes to support for policies to restrict emissions. However, consistent failure to deliver the promised action over the years shows that the UK model is no guarantee of success.

Australia's current political turmoil could yet benefit the climate. A coalition government will be forced to compromise and cooperate, and must look for popular support. Renewed focus on climate change would be a good start. 